\title{
$\mathbf{g} \mathbf{e}$
}

\section{ESPAÇO POLÍTICO}

\section{Iná Elias de Castro}

Universidade Federal do Rio de Janeiro

Espaço político, apenas como expressão, tem sido usado na geografia política no sentido de salientar tanto a interação entre o espacial e o político como a espacialidade da política ou mesmo a ideia de que há uma essência política no espaço como indicada por Lefèbre (1974). Esta é, por exemplo, a perspectiva da revista L'Espace Politique, surgida em 2007, cujo título se refere ao espaço da geografia política e tem por objetivo ultrapassar a divisão entre esta e a geopolítica, privilegiando os "temas fundamentais [que] se articulam em torno das noções de espaço e de territórios" (ROSIÈRE, 2007). Nessas abordagens, não é possível falar de um conceito ou mesmo uma noção de espaço político, mas de uma expressão que busca indicar o quanto espaço e política estão interligados, o que tem conduzido a algumas simplificações do tipo todo espaço é político ou toda política tem uma dimensão espacial.

A condição para buscar uma compreensão do espaço político como um conceito capaz de distinguir um objeto com qualidade, características distintas e significação para a reflexão e pesquisa na geografia política foi dada a partir do que Glassner et al. (1967) chamaram de "notável mudança de escala nas questões estudadas" pela disciplina após a década de 1960, que abriu a possibilidade para trabalhos na micro escala e para novos enfoques na abordagem de problemáticas características dos conflitos de interesses nos espaços subnacionais. Mas, algumas décadas foram necessárias para o processo de reconhecimento do espaço político como uma categoria de análise na disciplina. Este tem sido desde então um desafio para pensar o espaço e a política não como duas acepções distintas ou interligadas numa compreensão generalizante, mas como passíveis de um sentido próprio quando a política torna-se um atributo de um determinado espaço e este uma parte constitutiva daquela. Ou seja, quando este espaço qualifica a política que o diferencia de outros espaços e lhe atribui uma dinâmica própria da qual resulta um conteúdo diferenciado desse espaço.

Mas o recurso à noção de espaço político não está restrito à geografia, nem a disciplina foi pioneira na ideia, nem requer a materialidade do espaço que os geógrafos reivindicam em suas análises. 0 conceito de espaço político foi utilizado pioneiramente por Antony Downs (1957) como o espaço da competição eleitoral, na qual eleitores racionais se alinham num continuum de esquerda-direita. A partir de seus estudos, firmou-se uma corrente de análise espacial na ciência política norte americana, importante para estudos de competição eleitoral na qual se identificavam os espectros ideológicos da preferência dos eleitores como conservadores ou progressistas (STOKES, 1963). Sintetizando esta corrente, D'Alimonte (2003:392), explica que "por espaço político se entende a área de conflito que constitui a relação entre eleitores e partidos, num dado sistema político e num certo momento histórico". Mesmo se nesta perspectiva teórica o espaço seja metafórico e não considere qualquer componente que permita identificar este espaço abstrato da competição eleitoral como geográfico, é importante observar, como fizeram muitos geógrafos, o quanto existe de expressão espacial do voto, já identificada pela geografia eleitoral e o quanto o espaço político da competição eleitoral adquire visibilidade e materialidade nos espaços legislativos.

Mas a mudança de escala nos estudos de geografia política e o recurso às teorias desenvolvidas pela ciência política, já na década de 1970, favoreceram maior compreensão sobre como os conflitos políticos 
nos espaços subnacionais podem definir espaços qualitativamente diferentes. Neste período, Soja (1974) chamou a atenção para o problema da análise locacional dos conflitos de interesses, negligenciada nos estudos dos sistemas políticos. A crítica dos geógrafos americanos à ciência política recaiu sobre a necessidade de ênfase também nos fundamentos territoriais, na estrutura espacial e na expressão locacional do sistema político, além dos processos e das relações que o moldam. Nesta mesma linha, o autor criticou o fato de os sistemas - social e político - serem pensados, "em essência, frequentemente e totalmente divorciados de seu contexto geográfico" (op.cit.:59). Em reforço a esta observação, Soja (1974:61-62) utiliza a expressão espaço político como o espaço da comunidade política que se torna definida em termos territoriais e aponta a necessidade de maior interação entre a ciência política e a geografia como possibilidade para futuras pesquisas cooperativas (op.cit::66). Estimulados pela mesma problemática colocada na década, Cox, Reynolds e Rokkan (1974:29) afırmam que sistemas políticos são também sistemas espaciais, pois a localização tem significância crítica para os conflitos locacionais e para as suas soluções. Na década de 1970, o debate da geografia política norte americana sobre as abordagens locacionais do poder e dos conflitos foi uma resposta às análises sistêmicas da ciência politica e da sociologia que teimavam em ignorar a importância do espaço geográfico como parte da dinâmica das relações sociais. A partir da leitura atenta pelos geógrafos políticos das teorias da ciência política e da sociologia e da sua incorporação à agenda da disciplina, não era mais possível desconhecer que uma análise consistente dos arranjos espaciais dos conflitos sociais necessitava de uma compreensão mínima daquelas teorias. Estavam postos neste debate os elementos necessários ao avanço de uma compreensão da política como possibilidade, recurso e estratégia para as configurações do espaço.

A partir do final da década de 1970, Kevin Cox (1979) aprofunda as pesquisas sobre os conflitos espaciais nas alocações de políticas públicas, trazendo para a geografia o tema da "public choice", consolidado da ciência política. Nessa época, seus estudos eram sobre as estratégias políticas de grupos de pressão para atrair investimentos em políticas públicas favoráveis aos seus locais de moradia. Mas, em trabalhos posteriores, a questão do espaço como necessária, e não contingente, tanto às relações sociais como à política, contribuiu para as muitas possibilidades da relação espaço e política. Esta era evidente, não apenas como reflexão conceitual geral, mas, como problemática para a investigação empírica que focava determinados espaços como objeto para compreensão do fenômeno estudado (COX, 1991:161).

Mas, foi no início da década de 1990 que a ideia do espaço político como objeto de reflexão se colocou de maneira mais clara, embora ainda não completamente formulada. Esta, afinal, pressupunha ir além da perspectiva já amplamente aceita da interação entre a política e o espaço. Era neste sentido que um número especial da revista Espaces Temps (43-44, 1990), reeditado posteriormente como livro (LÉVY, 1991) começava com a indagação: "Espaço político, mas do que se trata exatamente?" Especialistas, não apenas geógrafos, foram convidados para responder brevemente à questão: "O que você entende por "espaço político"?" (LÉVY, 1991:17). Mas as respostas, naquele momento, não foram muito além da necessidade de reconhecer os espaços recortados pela função política das instituições de governo com a mediação das ações da sociedade civil. O espaço político foi percebido como uma dimensão da sociedade, como um nível espacial particular (LÉVY, 1991:209). Ainda era pouco claro o que seria este "nível espacial particular".

Porém, já era possível identificar nessas discussões a emergência de duas questões centrais: a necessidade de considerar Estado e governo como potências organizadoras dos conflitos entre o espaço político e o espaço civil e a regulação crescente da vida política e dos movimentos sociais (LÉVY, 1991:210). Mas é em obra posterior que Jacques Lévy (1994:15) propõe o espaço político como objeto a partir da consideração "da política (...) como um poder sobre as coisas, uma potência de transformação, seja direta, seja como patamar para outras ações e finalmente uma modificação do espaço civil (...)". Para o autor, o espaço político incorpora a vida social e os modos como esta pode modificar a geografia da decisão política, seja na geografia eleitoral, seja a intencionalidade do ator espacial individual para a ação concreta sobre o habitat. Analisando com um pouco mais de atenção, as questões levantadas pelo autor eram dirigidas ao esforço de renovação e ampliação da agenda da geografia política, sendo a ideia de espaço político um recurso importante para legitimar na disciplina as diferentes escalas e os recortes espaciais demarcados tanto pela ação do poder público, como aqueles das preferências eleitorais ou mesmo das escolhas residenciais. Mas, o espaço político considerado pelo geógrafo francês também poderia ser visto como o espaço da política, ou seja, o espaço de toda a sociedade, ou ainda, de modo mais específico, o espaço político torna-se uma invenção permanente da sociedade (LÉVY, 1994:248/258).

Ainda na década de 1990, Smith (1995:82) dá continuidade ao debate sobre a incorporação da teoria política para a análise das questões da geografia humana e os movimentos sociais são destacados pela capacidade de criar novos espaços políticos para novas geografias. Nesse trabalho, os movimentos sociais, como agentes de transformação sócio espaciais e de 
controle do poder, são focados tanto como novas formas coletivas de ação política nas sociedades pós-industriais como importantes nas escalas comunitárias para a configuração do que ele chama de espaço político.

Mesmo se a partir da década de 1970 até a década de 1990 a renovação da geografia política implicou a incorporação de conceitos da ciência política para compreender de que modo fenômenos políticos (tais como: ação coletiva; alocação de recursos governamentais; políticas públicas; decisão do eleitor; divisões político administrativas; movimentos sociais etc.) impactavam o espaço, ainda não estava claro como o espaço político era compreendido. Este era definido ora como o espaço da sociedade, ora como o espaço da resistência social, também como o espaço das escolhas eleitorais, ou mesmo como o que era chamado de espaço da política, aquele contemplado nas análises da geografia política, tanto na escala global como na escala nacional, regional ou local, especialmente nos espaços urbanos. Ou seja, com tantas possibilidades, o espaço político poderia ser todo e qualquer espaço tratado na geografia política.

No campo intelectual da democracia, as discussões sobre a necessidade de espaços e fóruns para a sua efetivação e legitimidade social (YOUNG, 2000), consolidou a discussão e as pesquisas sobre espaços políticos nas ciências sociais. Estes são categorizados, de modo mais geral, como espaços de lutas, de mobilizações por direitos, envolvimento dos cidadãos na governança, de reivindicações, de protestos etc. (DANIEL, 2002; KOEBEL, 2011; HOLSTON, 2013; CORNWALL, 2002, 2007; BROCKETT, 2015). Mas, estes espaços podem ser também aqueles das redes virtuais, sem materialidade, mas importantes por conectar movimentos em diferentes lugares do globo ou por facilitar a conexão entre o espaço virtual e o espaço concreto das mobilizações (CASTELLS, 2015; SMITH, 2015; DEANGELIS, 2015).

Nessa literatura, um bom exemplo da convergência do conceito de espaço político dos movimentos sociais para aquele aplicado na geografia encontra-se em Cornwall (2002). Os espaços políticos, objeto de análise da autora, possuem materialidade, representam arenas políticas dentro e além do Estado-nação e constituem "alguma coisa que pode ser criada, aberta e remodelada. (...) $\mathrm{O}$ ato de participação pode ser visto dando vida a espaços, bem como esculpindo novos espaços e criando novas formas sociais com seu próprio domínio e ímpeto" (Op.cit.p.2). Esses espaços estão associados a arenas políticas e à governança, cuja função é abrir canais de comunicação com o poder político institucionalizado com objetivo de ampliar o atendimento às demandas sociais por voz e inclusão. Frente às possibilidades e complexidade das formas de participação e dos espaços escolhidos e moldados para isto, a autora organiza uma tipologia de espaços políticos com base em critérios de: relação entre participantes e instituições; efemeridade, ou seja, espaços que se abrem com propósitos particulares e se fecham novamente; espaços escolhidos; espaços abertos das manifestações. Estas são algumas formas que assumem os espaços de ação de atores sociais e institucionais com objetivo de mudança, ou de conservação. Para a autora, diferentes possibilidades de participação e do envolvimento público na governança reforçam a cidadania e legitimam esses espaços. Ou seja, a questão central, subsumida nas suas reflexões conceituais e na pesquisa empírica, é: de que modo os espaços políticos forjados pela sociedade, em aliança ou em confronto com as instituições, adquirem funcionalidades e formatos diferenciados.

A ideia da necessidade de um espaço para a realização da política encontra-se também em Hanna Arendt, quando indica que o homem - como ser que age - constitui o centro da política (ARENDT, 1998:21-23). Elaborando a ideia do espaço político como um lugar, a autora argumenta que a ação política transborda das casas legislativas - espaços instituídos por excelência - para outros que constituem o seu repto. Mas, ao ponderar que o agir em comum dos homens acontece essencialmente no espaço político, Arendt (1998:7879) destaca a função primordial da política na relação entre a força, possibilidade do indivíduo ou da minoria, e o poder, potência da maioria, como base dos acordos necessários à ordem social e política.

Na discussão até aqui exposta, a questão mais geral da relação entre o espaço e a política é o substrato analítico de onde emerge o espaço político como objeto que merece atenção na geografia política. Tendo em vista as muitas possibilidades do conceito para a pesquisa na disciplina, em suas diferentes escalas, e para o estabelecimento de um diálogo enriquecedor com as ciências sociais, a reflexão sobre ele permanece na agenda.

Nesse diálogo, a expansão contemporânea da democracia de massas que resultou na multiplicação e visibilidade das esferas públicas e das arenas políticas tem balizado na geografia política a aplicação do conceito de espaço político (CASTRO, 2016). Nesta aplicabilidade do conceito há uma compreensão de que a política se revela em espaços concretos e que a qualificação do espaço pela política supõe uma dimensão da sociedade e possui no mínimo três atributos: a escala, a métrica e a substância (LÉVY, 1999), mas que interagem com a dimensão conflitual do mundo social. É neste sentido que atores políticos constroem escalas de ação (COX,1998) que conferem visibilidade e estabelecem recortes operacionais, cujas métricas se definem pelo alcance, na sociedade, dos impactos das decisões tomadas. Neste processo, os parlamentos e os espaços escolhidos pela 
sociedade para dar voz e visibilidade às suas demandas constituem espaços políticos que podem ser menos ou mais ativos.

O espaço político é então um tipo de espaço ao mesmo tempo de encontro, de debates e acordos sobre interesses conflitantes, pode ser ou não visível e acessível a todos e personifica a materialidade inerente à vida política que supõe não apenas pensar e falar, mas também o agir (CASTRO, 2012). 0 espaço político é então um lugar mobilizado para o confronto, onde os homens agem coletivamente com uma intenção, o lugar da defesa de interesses, da negociação e da disputa de poder sobre os acordos em relação às normas necessárias ao convívio pacífico entre diferentes visões de mundo. Há, pois na ação no espaço político uma dimensão instituinte, ou seja, uma conexão com o poder decisório governamental, qualquer que seja a sua escala.

Os espaços políticos podem ser pensados como objetos geográficos, uma vez que estes são simultaneamente disposição física das coisas e práticas sociais que ali ocorrem (GOMES, 2012:37). Porém, esta disposição e estas práticas apresentam diferenciações e a princípio esses espaços podem ser classificados segundo critérios de escala, métrica e substância, como já indicado, como fundamentos da sua visibilidade (reconhecimento), abrangência (alcance) e efetividade (efeitos desejados) respectivamente. Como outros autores nas ciências sociais citados já o fizeram, é possível estabelecer uma tipologia de categorias básicas de espaços políticos que podem ser tratados na geografia, com uma terminologia que remete à qualidade mais essencial de cada tipo considerado. Identificamos três tipos básicos de espaços políticos: exclusivos, limitados e abertos, tendo em vista a característica mais essencial da ação política em cada um.

Os Parlamentos, as Assembleias ou Câmaras Legislativas são decerto espaços políticos exclusivos, ou seja, são construídos e organizados essencialmente para o debate e a deliberação politica. Possuem ampla visibilidade e reconhecimento formais, são espaços onde se debatem interesses gerais conflitantes e cujos efeitos das decisões tomadas, sua substância, são erga omnes, ou seja, afetam o conjunto de cidadãos representados nos recortes territoriais da sua jurisdição e sua métrica, demarcada pela escala da ação. A ideia de exclusividade decorre do fato de que nas democracias representativas, apenas nas instituições legislativas é possível estabelecer normas impositivas a toda a sociedade no limite da sua circunscrição. Por dedução, os espaços da representação política são, pois, espaços políticos por excelência (BOBBIO, 1987).

Os espaços políticos limitados correspondem aos muitos espaços de debates e representação de interesses específicos na sociedade, institucionalizados e facultados por normas de participação em diferentes modelos de democracia como diferentes tipos de conselhos e de fóruns temáticos, associações de moradores (AZEVEDO, 2016). A qualificação de limitado remete mais à demarcação temática e decisória do que à escala dos seus efeitos. Ou seja, esses espaços podem ter resultados efetivos de suas ações em diferentes escalas, mas são restritos à agenda temática, como parte da sua atribuição.

Os espaços políticos abertos (CASTRO, 2016), que Cornwall (2002) chamou de espaços políticos de movimentos e momentos efêmeros, se expressam nas ruas e praças, lugares do cotidiano social que se metamorfoseiam em arenas de demandas, conflitos e ação, o que os investe de evidente caráter político (MACHADO FILHO, 2017). Estes são espaços da visibilidade e da performance política em bruto, ou seja, como forma que precisa ser interpretada (BUCCl, 2016). Sua escala e métrica são variáveis e instáveis, mas seus afeitos, como condição da sua substância podem afetar profundamente algumas decisões políticas de prazo mais longo, estabelecendo um nexo entre a "praça" e o "palácio", ou mais objetivamente, entre a sociedade e seus governantes. Estes são espaços de ação abertos a toda a sociedade, qualidade intrínseca aos espaços escolhidos para manifestações, protestos, passeatas, ocupações e tudo mais que a imaginação dos ativistas sociais decidir criar para alcançar seus objetivos políticos. Nunca é demais lembrar que quanto mais livres, numerosos e reconhecidos pela sociedade esses espaços, maior será o vigor da sua participação política na organização e defesa dos seus interesses.

A tipologia aqui exposta, muito mais sintética do que a proposta por Cornwall (2002), por exemplo, tem se mostrado útil para a geografia política na medida em que ela estabelece os três lugares privilegiados da ação política nas condições do mundo atual. 0 suposto é que o espaço político modela e é modelado por determinados tipos de ação da sociedade, tornando-se o lugar de debate, de discussão, de deliberação ou apenas de manifestação de vontades. Mas, o que é peculiar nesses espaços é a sua qualidade de estabelecer nexos entre os interesses que neles se expressam e a produção de normas favoráveis àqueles capazes de se impor aos demais, questão central da política. Se do ponto de vista da operacionalidade da pesquisa, a identificação desses três tipos de espaços pode parecer à primeira vista restritiva, na realidade ela tem o mérito de superar a imprecisão da ideia de que o espaço político é o espaço da competição eleitoral, ou o espaço da vida social ou ainda o espaço recortado pelas escalas de ação da gestão pública. Desse modo, a consideração da política supõe reforçar a perspectiva do Estado e governo como potências organizadoras da vida social tendo em vista as diferentes formas de mobilização da sociedade como potências instituintes 
que dialogam e se confrontam permanentemente com o status quo. Mas, deve ser destacado que estas ações qualificam um dado espaço onde é possível identificar e descrever um cenário real no qual normas são colocadas em questão. É nesta força dinâmica que se delineiam os cenários múltiplos e complexos dos espaços políticos, cada vez mais apropriados como objeto de pesquisa das ciências sociais, mas que merecem ser estudados e compreendidos pela geografia, tendo em vista o desafio que colocam para a compreensão mais objetiva da relação entre o espaço e o fato político. 
ARENDT, Hanna (1998) O que é política. Rio de Janeiro: Bertrand Brasil.

AZEVEDO, Daniel A. (2016) A democracia participativa como um sofisma: uma interpretação geográfica da democracia. UFRJ, Tese de Doutorado. Rio de Janeiro.

BOBBIO, Norberto (1987) Estado governo sociedade. Rio de Janeiro: Paz e Terra.

BROCKETT, Charles D. (2015) The repression/protest paradox in Central America.In: GOODWIN, J. ; JASPERS, J.M. (Edts) The social movements reader: cases and concepts. New Jersey: Wiley-Blackwell, 3 ed. p.363-369

BUCCI, Eugênio (2016) A forma bruta dos protestos. São Paulo: Companhia das Letras.

CASTELLS, Manuel (2015) The egyptian revolution. In: GOODWIN, J. ; JASPERS, J.M. (Edts) The social movements reader: cases and concepsts. New Jersey: Wiley Blackwel, 3ed. p.45-52

CASTRO, Iná E. (2012) O espaço político limites e possibilidades do conceito. In: Castro, I. E. Gomes, P. C. C,; Correa, L. (Orgs.) Olhares geográficos, Rio de Janeiro, Ed. Bertrand.

CASTRO, Iná E. (2016) Espaços políticos e novos desafios da relação Estado-sociedade no Brasil. In: SPOSITO, E. S..; SILVA, C.A.; SANT'ANNA, J. L. MELAZZO, E. S. (Orgs) A diversidade da geografia brasileira.Rio de Janeiro: Consequência. p. $95-112$

CORNWALL, Andrea (2002) Making spaces, changing spaces : situation participation in development. IDS Working Papers 170, October, Brighton

CORNWALL, Andrea; Coelho, Vera S (2007). Spaces for change? The politics of participation in new democratic arenas. In : CORNWALL, A.; COELHO, V. S. (Edts) SPACES FOR CHANGE ? London: Zed Books.

COX, Kevin ; REYNOLDS, David R. (1974) Locational approaches to power and conflict In: COX, K. ; Reynolds, D. R.; ROKKAN, S. (Edts) Locational approaches to power and conflict. Sage Publications.

COX, Kevin R. (1979) Location and public problem.Chicago: Maaroufa Press.

COX, Kevin (1991) Classes, localisations et territoires. In : LÉVY, J. (Org.) Géographies du politique. Paris: Presses de F.N.S.P./ESPACESTEMPS, p.161-173

COX, Kevin (1998). Spaces of dependence, spaces of engagement and the politics of scale, or: looking for local politics. Political Geography 17, p. 1-23.

D'ALIMONTE, Roberto (2003) Espaço político. In : BOBBIO, Norberto et. al. Dicionário de Política. Brasília: Ed. UnB.

DANIEL, Justin (2002) L'espace politique aux Antilles françaises. Révue Ethnologie Française, Vol.32, p.589-600

DEANGELIS, Enrico (2015) L'espace politique virtuel avant et aprés la chute de Moubarak: une critique des réseaux sociaux en Egypte. Egypte/Monde Arabe, n¹2, p.195-227

DOWNS, Antony (1957) An economic theory of democracy. New York: Harper.

GLASSNER, Martin I.; DE BLIJ, Harm J. (1967) Systematic political geography. New Jersey: John Wiley \& Sons.

GOMES, Paulo Cesar C. (2012) GOMES, Paulo Cesar da Costa (1997). "Geografia fin-de-siècle: o discurso sobre a ordem espacial do mundo e o fim das ilusões". In: CASTRO, I. E. et al. (Orgs.) Explorações geográficas. Rio de Janeiro: Ed. Bertrand.

HOLSTON, James (2013) Cidadania insurgente. Companhia das Letras. São Paulo.

KOEBEL, Michel (2011) Décentralisation et autonomie de l'espace politique local. Révue Savoir/Agir, Nº15, p.39-47

LEFÈBVRE (1974) La production de l'espace. Paris: Anthropos. (disponível em português)

LÉVY, Jacques (1991). Espèces d'espaces politiques. In: LÉVY, J. (Org.) Géographies du politique. Paris: Presses de F.N.S.P./ESPACESTEMPS.

LÉVY, Jacques (1994). L'espace Légitime. Paris: Presses de la Fondation Nationale des Sciences Politiques.

LÉVY, Jacques (1999). Le tournant géographique. Paris: Belin.

MACHADO FILHO, Guilherme (2017) Espaços da política: a relação entre o espaço político das Assembleias e o 
espaço político das ruas no contexto das manifestações políticas brasileiras contemporâneas. UFRJ, Dissertação de Mestrado, Rio de Janeiro

ROSIÈRE, Stéphane (2007) Comprendre L'Espace Politique. L'Espace Politique, n.1.

SMITH, Graham (1996) Teoria política e geografia humana. In: Gregory, D. et al. Geografia humana. Zahar. Rio de Janeiro.

SMITH, Jackie (2015) The transnational network for democratic globalization. In: GOODWIN, J. ; JASPERS, J.M. (Edts) The social movements reader: cases and concepsts. New Jersey: Wiley Blackwel, 3ed. p.184-195

SOJA, Edward W. (1974) A paradigm for geographical analysis of political systems. In: COX, K. ; Reynolds, D. R.; ROKKAN, S. (Edts) Locational approaches to power and conflict. Sage Publications. p.43-71

STOKES, D. (1963) Spatials models of party competition. American Political Science Review, LVII.

YOUNG, Iris M. (2000) Inclusion and democracy. University Press, Oxford.

\section{Leituras recomendadas}

CASTRO, Iná E. (2012) O espaço político limites e possibilidades do conceito. In: CASTRO, I. E. GOMES, P. C. C,; CORREA, L. (Orgs.) Olhares geográficos, Rio de Janeiro: Ed. Bertrand.

CASTRO, Iná E. (2016) Espaços políticos e novos desafios da relação Estado-sociedade no Brasil. In: SPOSITO, E. S..; SILVA, C.A.; SANT'ANNA, J. L. MELAZZO, E. S. (Orgs) A diversidade da geografia brasileira. Rio de Janeiro: Consequência. p.95-112

CORNWALL, Andrea; COELHO, Vera S (2007). Spaces for change? The politics of participation in new democratic arenas. In : CORNWALL, A.; COELHO, V. S. (Edts) Spaces for Change? London: Zed Books.

LÉVY, Jacques (1991). Espèces d'espaces politiques. In: LÉVY, J. (Org.) Géographies du politique. Paris: Presses de F.N.S.P./ESPACESTEMPS, 1991.

LÉVY, Jacques (1994). L'espace Légitime. Paris: Presses de la Fondation Nationale des Sciences Politiques. 